\title{
International association for education in ethics (IAEE)
}

Published online: 14 March 2017

(C) Springer International Publishing AG 2017

In April 2011 the International Association for Education in Ethics was officially established. At the initiative of UNESCO, a group of international scholars in ethics education created this global platform for exchange of experiences in the teaching of ethics. The Secretariat is established at the Center for Healthcare Ethics, Duquesne University, Pittsburgh, USA (www.ethicsassociation.org).

The goals of IAEE are to exchange and analyze experiences with the teaching of ethics in various educational settings, to promote the development of knowledge and methods of ethics education, to function as a global centre of contact for experts in this field, to promote contacts between members from countries around the world and to enhance and expand the teaching of ethics at national, regional and international levels.

The IAEE organizes annual conferences. International conferences have taken place in Pittsburgh, USA (2012), Ankara, Turkey (2014), Curitiba, Brazil (2015), and Logroño, Spain (2016). Next conferences are scheduled for Mangalore, India (15-18 November 2017), Stellenbosch, South Africa (3-5 October 2018), and Porto, Portugal (22-24 July 2019). Conferences will feature keynote lectures from experts and parallel sessions regarding a wide variety of fields. These fields of study include: bioethics, medical ethics, nursing ethics, pharmacy ethics, dental ethics, science ethics, engineering ethics, philosophical ethics, religious ethics and business ethics.

Those who are interested in becoming members of the International Association for Education in Ethics or would like to attend its annual conferences should visit www.ethicsassociation.org.

The International Journal of Ethics Education will be included in membership of IAEE. Members are also entitled to a reduced registration fee for the conferences. For joining IAEE, register as a member on the website (www.ethicsassociation.org).

For more information: contact Professor dr. Henk ten Have, Center for Healthcare Ethics, Duquesne University, Pittsburgh, USA (tenhaveh@duq.edu).

For the upcoming 2017 I.E. conference in Mangalore, India: info.iaee5@yenepoya.edu.in 